\title{
Pain during Arteriovenous Fistula Cannulation in Chronic Renal Patients on Hemodialysis
}

\author{
Olvani Martins da Silva1,2, Eluani Rigon², Jéssica Vanessa Corradi Dalazen², \\ Aline Bissoloti ${ }^{3}$, Eneida Rejane Rabelo-Silva1 \\ ${ }^{1}$ Graduate Programa at Federal University of Rio Grande do Sul, Porto Alegre, RS, Brazil \\ ${ }^{2}$ Santa Catarina State University, Chapecó, SC, Brazil \\ ${ }^{3}$ West Renal Clinic, Chapecó, SC, Brazil \\ Email: olvanims@hotmail.com, eluani_rigon@hotmail.com, jeh_dallazen@hotmail.com, \\ aline_biss@hotmail.com, eneidarabelo@gmail.com
}

How to cite this paper: da Silva, O.M., Rigon, E., Dalazen, J.V.C., Bissoloti, A. and Rabelo-Silva, E.R. (2016) Pain during Arteriovenous Fistula Cannulation in Chronic Renal Patients on Hemodialysis. Open Journal of Nursing, 6, 1028-1037.

http://dx.doi.org/10.4236/ojn.2016.612098

Received: November 18, 2016

Accepted: December 25, 2016

Published: December 28, 2016

Copyright $\odot 2016$ by authors and Scientific Research Publishing Inc. This work is licensed under the Creative Commons Attribution International License (CC BY 4.0).

http://creativecommons.org/licenses/by/4.0/

\begin{abstract}
This study aimed to evaluate pain intensity in chronic renal patients under hemodialysis during the arteriovenous fistula cannulation. It was a cross-sectional study conducted in a hemodialysis clinic in the second semester of 2014. 70 individuals participated in the research and were assessed by the visual analogue scale. The project was approved with opinion number 453.508-2013. During cannulation, the pain reported was moderate in $58.5 \%$ of patients, intense in $30 \%$ and mild in $11.5 \%$. There was no association between the occurrence of pain in relation to gender, shift and time of hemodialysis. The study points out to the need for pre-cannulation analgesia to improve comfort during the procedure.
\end{abstract}

\section{Keywords}

Pain, Arteriovenous Fistula, Renal Dialysis

\section{Introduction}

The presence of vascular access is vital for patients with chronic kidney disease in hemodialysis [1], in order to establish a proper blood flux and guarantee the blood purification [2], ensuring the quality of dialysis.

To carry out the hemodialysis treatment, the arteriovenous fistula (AVF) cannulation must be performed three to four times a week [2], approximately 300 punctures per year [3], with thick needles [4]. Despite this observation, AVF remains as the main choice of nephrologist teams, because it has minor risk of infection, assures proper functioning for a period of five years and requires lower demand for maintenance in- 
terventions [1].

Although the cannulation technique influences on survival rate of the access [5], there is no universally standardized method to apply this technique. However, rotation is recommended in the points of punctures [6] [7].

Three puncture techniques are used by hemodialysis professionals: area puncture, rope-ladder and buttonhole [8] [9]. Some authors point out that the most widely used technique in the world, including Europe and the United States, is the rope-ladder [8] [9] [10]. In Brazil, this is the preferred technique. It consists in alternating puncture sites as an attempt to prevent aneurysm formation, stenosis and repeated trauma by multiple punctures [11] [12].

In a study aimed to measure the pain associated with AVF cannulation, comparing the buttonhole with the rope-ladder technique with sharp needle, the first seemed less painful, although without statistically significant results [13]. On the other hand, other authors who compared the effects of the traditional and the buttonhole method, demonstrated statistically significant results in favor of the buttonhole method for pain reduction. In addition, another finding in this study was that the use of this technique reduced pre-cannulation anxiety [14].

The pain caused by AVF cannulation is an important aspect to be evaluated in the patient by the nursing professionals. This subject should be marked in the first instance, because it is a stressful issue when patients need to accept AVF as the mean to make a vascular access [4]. Often, the fear of needles and the pain caused by the puncture can provoke discomfort and anxiety, requiring the use of local anesthetic products in the pre-cannulation [9].

In this sense, the pain assessment during AVF cannulation by nursing staffs should be a daily practice in dialysis services. However, this principle has been little used, and studies that approach this topic with the due attention are rare. To fill this knowledge gap, this study aims to measure the pain intensity in chronic renal patients under hemodialysis during AVF cannulation by using the Visual Analogue Scale (VAS).

\section{Methods}

\subsection{Type of Study}

Cross-sectional study conducted in a hemodialysis clinic that assists 150 chronic renal patients. The data collection period was from October to December 2014.

\subsection{Sample and Participants}

150 patients under dialysis treatment were considered for the sample calculation. It was considered a significance level of $5 \%$ and $80 \%$ of power, besides estimation for inclusion of 60 patients. In this study, $10 \%$ of losses were estimated, and at the end, 70 patients were included in the sample.

Inclusion criteria were adult patients, regardless of treatment time. Patients with cognitive and visual deficit as well as the ones who became inpatients during the data collection period were excluded. 


\subsection{Data Collection and Instrument}

For the data collection, a questionnaire prepared by the authors was applied, which contained variables (gender, age, education, shift in treatment and time of treatment of hemodialysis). Multiple choice questions related to the presence or absence of pain during cannulation and type of pain (piercing, cutting, irradiated). The pain intensity produced during AVF cannulation by the rope-ladder technique was measured by a unidimensional scale that examines only one characteristic [15]. The Visual Analogue Scale (VAS) was used as a first-choice instrument due to its ease of application and reproduction [16]. For pain classification, the patient is requested to select one of the options in the scale that goes from zero (no pain) to ten (worst pain imaginable), indicating the intensity of their pain at the moment [17]. As a reference for pain intensity, scores ranged from 0 to $3.9 \mathrm{~cm}$ for mild pain, from 4.0 to $7.9 \mathrm{~cm}$ for moderate pain, and from 8.0 to $10.0 \mathrm{~cm}$ for severe pain [18]. All instruments were applied in a hemodialysis room, immediately after the AVF cannulation procedure.

The project was approved by the Committee of Ethics in Research Involving Human Subjects of Universidade do Estado de Santa Catarina (UDESC) with opinion number 453,508 of 11/8/2013, 20138913.4.0000.0118 CAAE. All patients included in the study have read and agreed to participate by signing the informed consent form.

\subsection{Data Analysis}

The data were inserted in the Statistical Package for Social Sciences (software version 18.0). Continuous variables were expressed as mean and standard deviation, and the categories with relative frequencies and absolute number. Chi-square test and Fisher's exact test were used, with a significance level of $5 \%$, to verify the if there was any association between the gender, shift, period of the dialytic procedure variables and period of hemodialysis with pain.

\section{Results}

The sample consisted of 70 patients, women being predominant. The average age was $60 \pm 19$, and approximately half of the sample had finished elementary school and had 4-hour dialysis session, mainly in the evening period.

When evaluated with VAS, for the presence of pain during the arteriovenous cannulation, $41(58.5 \%)$ of patients mentioned moderate pain, 21 (30\%) severe pain and 8 (11.5\%) mild pain. These data are shown in Table 1. Regarding pain characteristics, 36 (51\%) classify it as penetrating and $34(49 \%)$ describe as cutting.

Table 2 presents the pain perception by the patient under hemodialysis during the AVF puncture concerning gender, shift and time the treatment is carried out. No association was observed between the analyzed variables $(p<0.05)$.

\section{Discussion}

This is one of the few studies that approach the assessment of pain during AVF puncture. Pain reports of patients by scale assessment shows varied intensity. Most of them 
Table 1. Characteristic of patients and pain during cannulation of arteriovenous fistula.

\begin{tabular}{cc}
\hline Variables & $\mathbf{N}=70$ \\
Gender & \\
Sex (female) & $37(53 \%)$ \\
Education & \\
Not attended school & $12(17 \%)$ \\
Elementary School & $39(56 \%)$ \\
High School & $19(27 \%)$ \\
Hemodialysis performance shift & \\
Morning & $23(33 \%)$ \\
Afternoon & $28(40 \%)$ \\
Evening & $19(27 \%)$ \\
Characteristic of pain & \\
Penetrating & $8(11.5 \%)$ \\
Moderate & $41(58.5 \%)$ \\
Intense & $21(30 \%)$ \\
\hline
\end{tabular}

Table 2. Pain perception and association with gender, shift and time the hemodialysis is carried out.

\begin{tabular}{ccccc}
\hline \multicolumn{5}{c}{ Pain intensity } \\
\hline & Mild pain n (\%) & Moderate pain n (\%) & Severe pain (\%) & Total \\
\hline Gender & & & \\
Male & $4(12.5 \%)$ & $20(62.5 \%)$ & $8(25.0 \%)$ & $32(100.0 \%)$ \\
Female & $4(10.5 \%)$ & $21(55.3 \%)$ & $13(34.2 \%)$ & $38(100.0 \%)$ \\
& & & \\
Morning & $1(4.3 \%)$ & $12(52.2 \%)$ & $23(100.0 \%)$ \\
Afternoon & $3(10.7 \%)$ & $19(67.9 \%)$ & $28(100.0 \%)$ \\
Evening & $4(21.1 \%)$ & $10(52.6 \%)$ & $5(26.3 \%)$ & $19(100.0 \%)$ \\
& How long hemodialysis has been performed & $17(32.1 \%)$ & $53(100.0 \%)$ \\
Up to 5 years & $6(11.3 \%)$ & $30(56.6 \%)$ & $4(23.5 \%)$ & $17(100.0 \%)$ \\
\hline
\end{tabular}

are moderate pain, but with a significant percentage of severe pain.

The reported characteristics by patients are according those described by Aitken et al. [19] - traumatic and nociceptive pain. Traumatic pain is a type of acute pain caused by injuries, diagnostic procedures or treatments, invasive procedures that involves the use of sharp instruments through the tissues [20], which is very similar to the vessel cannulation by needles. 
When asked about painful sensations during procedures, although some have not referred to pain, for all the patients evaluated the pain was present when the analog scale was used. The use of instruments to assess pain intensity is the best way to interpret and understand the pain experienced by the patient, improving the assistance offered by the team to meet individual needs [15].

Little concern with comfort and pain during AVF cannulation were the determining factors that hamper hemodialysis treatment adherence in a study with 45 chronic renal patients [21]. Intense pain during the procedure generates anxiety and fear regarding a new puncture, often discouraging the treatment [21].

In a study that investigated the difficulties and complications in the introduction of the buttonhole technique for AVF at home with a native vein-and with a visual-digital scale to assess pain during the punctures-, it was observed that pain intensity produced by the buttonhole technique was softer when compared to the traditional technique [7].

In our study, we found no association among pain with genre, shift and time of hemodialysis treatment. Concerning genre, the result is in accordance with the study carried out by Aitken et al. [19] and Celick et al. [3], in which there was no significant relationship between pain and genre [3] [19]. However, in the study of Sabitha et al. [22], by correlating the perception of pain and age, gender and time variables, the AVF use time and educational background of the analyzed individuals, the authors found that pain intensity related to AVF puncture was associated with women [22]. Figueiredo et al. [13] also found slightly elevated degree of pain in women compared to men, although this result was not statistically significant [13].

Women tend to have lower pain threshold compared to men, because pain is influenced by mechanisms that can stimulate or inhibit the sensations. The difference in the pain threshold between men and women can be related to hyperalgesia, or to the hypoactivity of the inhibitory system of pain related to women. Sexual hormones explain this difference in pain perception [23].

In this study, the hemodialysis time was influenced by the duration of the arteriovenous access-the longer the time in hemodialysis, the higher the use of AVF. Thus this result corroborates the ones obtained by Sabitha et al. [22], researchers who have found no correlation with the duration of use of the fistula or the number of punctures to which it was submitted.

A study of 461 patients assessed the prevalence and nature of pain in AVF and its impact on the quality of life and adherence of patients with dialysis-the result showed that $20.4 \%$ of patients had severe pain caused by cannulation during the first year, and $7.6 \%$ of the patients had severe pain after the first year of cannulation [19].

In relation to the shift of dialysis treatment, there was no influence regarding pain, result similar to the one found by Dalaroza et al. [24], who investigated pain felt by the elderly-89 (51.15\%) individuals reported no specific time for the pain onset. It should be noted that in the study of Dalarosa et al. [24] no invasive procedure was used.

The search for alternatives to minimize pain at the moment of the arteriovenous fis- 
tula puncture comes from studies such as the one by Novarte et al. [25], who used sensorial hyperstimulation, with a tourniquet called "millimetric smarchs", and compressed the AVF member causing discomfort but in a way to not compromise circulation. The compression limit was evaluated by the patient in consensus with the nursing [25].

The evaluations were carried out during ten sessions and the application of extra compression was alternated with the usual compression. The results of this study indicate that an extra compression in the member with the access substantially reduced the pain degree during venipuncture. On the other hand, in the arterial puncture the pain reduction was not significant. Pain reduction makes interesting the use of the millimetric tourniquet (smarch) in comparison with the usual method [25].

Another alternative to minimize pain was performed with frozen needles-in this case, the pain intensity was compared with a pain assessment scale during the fistula cannulation with the insertion of needles at room temperature and needles frozen at $-8^{\circ} \mathrm{C}$. Frozen needles caused less pain than the needles at room temperature [26].

Reinforcing the findings of the effectiveness of low temperature, a randomized clinical trial with a sample of 60 patients investigated the effect of cryotherapy by applying ice between the thumb and the index finger of the hand that did not have AVF (contralateral). Ten minutes before cannulation, the cold was applied and lasted all the cannulation procedure. Cryotherapy showed to be effective in reducing pain during the arteriovenous fistula cannulation. But for the authors, although the study obtained favorable results, the fact that it was conducted in a single medical center does not enable a generalization for their findings [22].

Using the cold experiment, Thomás et al. [4] found the occurrence of pain during AVF cannulation in comparison to anesthetic ointment and local cold. In the first week of analysis, the patients were subjected to the EMLA anesthetic ointment; in the second week a placebo was used-a moisturizing cream-and in the third week the ice application took place. The pain was measured by the visual analogue scale and a numeric scale [4].

The use of EMLA anesthetic ointment was more effective for the assessment of patients. The ice showed no favorable outcome, condition that, according to the authors, can be associated to the discomfort caused by the technique, since the study took place in a period of low temperature [4].

The use of the anesthetic was also tested by Celick et al. [3] who used lidocaine vapocoolant spray, a placebo and EMLA cream. The authors noted that EMLA application showed lower pain scores compared to other interventions. No patient presented severe pain with the use of EMLA or vapocoolant spray, and the latter was considered as effective as EMLA to prevent mild to moderate pain during cannulation [3].

Although the EMLA efficacy is recognized and used in hemodialysis patients, it is not a standard practice for nursing staffs. In this sense, Soler and Romero [2] developed a study to justify the use of anesthetic ointments to minimize the pain during the puncture in patients under hemodialysis [2].

Its efficacy was proven by a decrease of the pain sensation by applying the anesthetic 
ointment in three dialysis sessions, using the same needles, and keeping the same puncture technique. The authors highlight that nurses may suggest the use of ointment, but it is up to the patients accept it or not [2].

The result of studies investigating the dull needle puncture technique, although not having the main outcome regarding pain, corroborate the topic by reporting pain reduction through the buttonhole cannulation technique. Since this technique uses sharp needles during the intubation stage, which are introduced in the exact point of the previous puncture, keeping the same angle and consistency in the penetration carried out by a single nurse (or two nurses), and after the tube formation starts the dull needles procedure [5] [7] [11], this could be the possible reason for minimizing the pain by reducing the trauma, without damaging the endothelium.

Favorable results in minimizing pain using this technique were found by Pergolotti; Rich; Lock [14], Silva et al. [27], as well as by Evans [8] in a bibliographic revision in which pain and anxiety were reduced and patients have improved the quality of life.

Pain assessment is a challenging task [15], as well as the measures used for its management, which have potentialities but also-like any other technique-some disadvantages such as the EMLA anesthetic, which despite presenting effectiveness, starts to act 45 - 60 minutes after its application. This requires more time to prepare the cannulation area [3] and, even being effective, does not completely eliminate pain [4].

In its turn, the vapocoolant spray showed, by ultrasound examination, that it does not cause significant difference in the vessel diameter and in the flow volume after application in healthy adults and dialysis patients, but the concern is related to probable vasoconstrictors effects, which can cause obstruction in the AVF during the application [3].

Cryotherapy was pointed out by the authors as a technique with limitations due to the small number of samples. Moreover, the diabetes patients were not uniformly distributed in groups, and thus the found results need to be confirmed by studies with larger samples [22].

Buttonhole cannulation uses high number of dull needles [11], and studies have discussed the increased risk of local and systemic infections through the use of this technique [6] [8] [28] [29] [30].

Recently a randomized clinical trial, comparing the buttonhole and the rope-ladder technique, evaluated 131 patients and found no pain reduction with the use of button technique compared to the traditional technique. Despite the methodological rigor of the study, the weakness resides on the use of local anesthetic by patients before the arteriovenous cannulation, which can alter results [31].

This data are supported by a systematic review that included 23 studies, and points out that the technique does not minimize the overall cannulation pain. This suggests that its use is only recommended to patients with specific indications, such as patients with short, deep or tortuous fistulas. And also warns that there is low scientific evidence in the studies on the subject and encourages the implementation of more robust methodological designs [30]. 
In any case, the appropriate monitoring and surveillance for pain detection in vascular access of hemodialysis patients is essential for a good acceptance of the treatment.

\section{Study Limitations}

One of the limitations of the study is that the pain during the fistula puncture by the rope-ladder technique was evaluated in a single occasion. Furthermore, we used the same approach for all patients, including those above 60 years of age.

\section{Conclusion}

The use of VAS showed the presence of moderate pain in most patients. No association between pain and gender, treatment period and hemodialysis shifts was found.

\section{Implications for Clinical Practice}

This study points out the need for an effective pain assessment before the AVF puncture, which can serve as a starting point for the elaboration of protocols for pain management in hemodialysis.

We suggest experimental studies to compare different pharmacological and nonpharmacological approaches as alternatives to minimize pain.

\section{References}

[1] Ribeiro, R.C.H.M., Miranda, A.L.L., Cesarino, C.B., Bertolin, D.C., Ribeiro, D.F. and Kusumota, L. (2009) Learning Needs of Professional Nurses to Care for Patients with Arteriovenous Fistula. Acta Paulista de Enfermagem, 22, 515-518. http://www.scielo.br/scielo.php?script=sci arttext\&pid=S0103-21002009000800012

[2] Soler, A.M. and Romero, J.A.P. (2010) Recommendation of Anesthesic Ointment EMLA in the Puncture to Patients Submitted to Periodic Hemodialysis. Recién, 1, 1-5. https://rua.ua.es/dspace/bitstream/10045/44811/1/RECIEN 01 05.pdf

[3] Çelik, G., Özbek, O., Yılmaz, M., Duman, I., Özbek, S. and Apiliogullari, S. (2011) Vapocoolant Spray vs Lidocaine/Prilocaine Cream for Reducing the Pain of Venipuncture in Hemodialysis Patients: A Randomized, Placebo-Controlled, Crossover Study. International Journal of Medical Sciences, 8, 623-627. https://doi.org/10.7150/ijms.8.623

[4] Tomás, P.A., Ambou, I.P., Baylach, C.M.P. and Joaquín, C.B. (2014) Pain Assessment in an Arteriovenous fistule Puncture for Hemodialysis Using Anaesthetic Cream vs Ice. Enfermería Nefrológica, 17, 11-15. http://scielo.isciii.es/scielo.php?script=sci $\operatorname{arttext\& pid=S2254-28842014001100002}$

[5] Pueyo, C.G., et al. (2011) Vascular Access Puncture in Haemodialysis Is a Necessity. The Buttonhole Method Is an Option. Revista Oficial de la Sociedad Española de Enfermería, 14, 30-36. http://scielo.isciii.es/scielo.php?script=sci arttext\&pid=S1139-13752011001100005

[6] Chow, J., Rayment, G., San Miguel, S. and Gilbert, M. (2011) A Randomised Controlled Trial of Buttonhole Cannulation for the Prevention of Fistula Access Complications. Journal of Renal Care, 37, 85-93. https://doi.org/10.1111/j.1755-6686.2011.00211.x

[7] Castro, M.C.M., et al. (2010) Arteriovenous Fistula Cannulation by Buttonhole Technique Using Dull Needle. Jornal Brasileiro de Nefrologia, 32, 277-281.

http://www.ncbi.nlm.nih.gov/pubmed/21103692 
[8] Evans, L.M. (2012) Buttonhole Cannulation for Haemodialysis: A Nursing Review. Renal Society of Australasia Journal, 8, 146-151. http://www.renalsociety.org/public/6/files/documents/RSAJ/2012.11/evans.pdf

[9] McCann, M., Einarsdottir, H., Waeleghem, J.P.V., Murphy, F. and Sedgwick, J. (2009) Vascular Access Management II: AVF/AVG Cannulation Techniques and Complications. Journal of Renal Care, 35, 90-98. https://doi.org/10.1111/j.1755-6686.2009.00095.x

[10] Van Loon, M.M., Goovaerts, T., Kessels, A.G.H., Van der Sande, F.M. and Tordoir, J.H.M. (2010) Buttonhole Needling of Haemodialysis Arteriovenous Fistulae Results in Less Complications and Interventions Compared to the Rope-Ladder Technique. Nephrology Dialysis Transplantation, 25, 225-230. https://doi.org/10.1093/ndt/gfp420

[11] Silva, D.M., Gurgel, J.L. and Escudeiro, C.L. (2015) Cannulation of Arteriovenous Fistulas by the Buttonhole Technique: A Case Study. Online Brazilian Journal of Nursing, 14, 197 204. https://doi.org/10.17665/1676-4285.20155099

[12] Silva, G.S.T., et al. (2010) Initial Experience with the Buttonhole Technique in a Brazilian Hemodialysis Center. Jornal Brasileiro de Nefrologia, 32, 257-262. http://www.ncbi.nlm.nih.gov/pubmed/21103688

[13] Figueiredo, A.E., Viegas, A., Monteiro, M. and Poli-de-Figueiredo, C.E. (2008) Research into Pain Perception with Arteriovenous Fistula (AVF) Cannulation. Journal of Renal Care, 34, 169-172. https://doi.org/10.1111/j.1755-6686.2008.00041.x

[14] Pergolotti, A., Rich, E. and Lock, K. (2011) The Effect of the Buttonhole Method vs. the Traditional Method of AV Fistula Cannulation on Hemostasis, Needle Stick Pain, PreNeedle Stick Anxiety, and Presence of Aneurysms in Ambulatory Patients on Hemodialysis. Nephrology Nursing Journal, 38, 333-336. http://www.ncbi.nlm.nih.gov/pubmed/21928609

[15] Bottega, F.H. and Fontana, R.T. (2010) Pain as the Fifth Vital Sign: Use of the Assessment Scale by Nurses in General Hospital. Texto \& Contexto Enfermagem, 19, 283-290. https://doi.org/10.1590/S0104-07072010000200009

[16] Saça, C.S., Carmo, F.A., Arbuleia, J.P.S., Souza, R.C.X., Alves, A.S. and Rosa, B.A. (2010) Pain as 5th Vital Sign: Role of the Nursing Staff in a Private Hospital with Management of Basic Health Unit. Journal of the Health Sciences Institute, 28, 35-41.

https://www.unip.br/comunicacao/publicacoes/ics/edicoes/2010/01 jan-mar/V28 n1 2010 p35-41.pdf

[17] Martinez, J.E., Grassi, D.C. and Marques, L.G. (2011) Analysis of the Applicability of Different Pain Questionnaires in Three Hospital Settings: Outpatient Clinic, Ward and Emergency Unit. Revista Brasileira de Reumatologia, 51, 299-308.

http://www.scielo.br/pdf/rbr/v51n4/v51n4a02

[18] Rubbo, A.B. (2010) Visual Analogue Scale in the Evaluation of Postoperative Pain Intensity of Bariatric Surgery Independent of the Use of Analgesics. Thesis Doctorate, Medical Sciences College in Santa Casa de São Paulo, São Paulo.

[19] Aitken, E., McLellan, A., Glen, J., Serpell, M., Mactier, R., (2013) Clancy M. Pain Resulting from Arteriovenous Fistulae: Prevalence and Impact. Clinical Nephrology, 80, 328-333. https://doi.org/10.5414/CN107917

[20] Moreno, E.A., Carvalho, A.A.S. and Paz, E.P.A. (2014) Pain in Child Undergoing Venipuncture: Effects of an Anesthetic Cream. Escola Anna Nery Revista de Enfermagem, 18, 392-399. https://doi.org/10.5935/1414-8145.20140056

[21] Madeiro, A.C., Machado, P., Bonfim, I.M., Braqueais, A.R. and Lima, F.E.T. (2010) Adherence of Chronic Renal Insufficiency Patients to Hemodialysis. Acta Paulista de Enfermagem, 23, 546-551. https://doi.org/10.1590/S0103-21002010000400016 
[22] Sabitha, P.B., Khakha, D.C., Mahajan, S., Gupta, S., Agarwal, M. and Yadav, S.L. (2008) Effect of Cryotherapy on Arteriovenous Fistula Puncture-Related Pain in Hemodialysis Patients. Indian Journal of Nephrology, 18, 155-158.

https://doi.org/10.4103/0971-4065.45290

[23] Palmeira, C.C.A., Ashmawi, H.A. and Posso, I.P. (2011) Sex and Pain Perception and Analgesia. Revista Brasileira de Anestesiologia, 61, 814-828.

https://doi.org/10.1016/S0034-7094(11)70091-5

[24] Dellaroza, M.S., et al. (2008) Characterization of Chronic Pain and Analgesic Approaches among Community-Dwelling Elderly. Revista da Associação Médica Brasileira, 54, 36-41. https://doi.org/10.1590/S0104-42302008000100018

[25] Navarrete, I.G., et al. (2005) A Nursing Action: Trying to Alleviate Pain in Haemodialysis Punctures. Revista de la Sociedad Española de Enfermería Nefrológica, 8, 231-236 http://scielo.isciii.es/scielo.php?script=sci arttext\&pid=S1139-13752005003300006

[26] Alvarez, R.C., Pla, J.P. and Hidalgo, S.F. (2004) Leve of Pain in the Arteriovenous Fistula Comparing Frozen Needles with Room Temperature Needles. Revista de la Sociedad Española de Enfermería Nefrológica, 7, 74-76.

http://scielo.isciii.es/scielo.php?script=sci $\operatorname{arttext\& pid=S1139-13752004002200002}$

[27] Silva, D.M., Gurgel, J.L., Escudeiro, C.L. and Ferreira, H.C. (2015) Patient Satisfaction with the Buttonhole Technique. CogitareEnferm, 20, 483-488.

http://revistas.ufpr.br/cogitare/article/viewFile/41576/26299

[28] Muir, C.A., et al. (2014) Buttonhole Cannulation and Clinical Outcomes in a Home Hemodialysis Cohort and Systematic Review. Clinical Journal of the American Society of Nephrology, 9, 110-119. https://doi.org/10.2215/CJN.03930413

[29] Lok, C.E., Sontrop, J.M., Faratro, R., Chan, C.T. and Zimmerman, D.Z. (2014) Frequent Hemodialysis Fistula Infectious Complications. Nephron Extra, 4, 159-167. https://doi.org/10.1159/000366477

[30] Wong, B., et al. (2014) Buttonhole Versus Rope-Ladder Cannulation of Arteriovenous Fistulas for Hemodialysis: A Systematic Review. American Journal of Kidney Diseases, 64, 918-936. https://doi.org/10.1053/j.ajkd.2014.06.018

[31] MacRae, J.M., Ahmed, S.B., Atkar, R. and Hemmelgarn, B.R. (2012) A Randomized Trial Comparing Buttonhole with Rope Ladder Needling in Conventional Hemodialysis Patients. Clinical Journal of the American Society of Nephrology, 7, 1632-1638.

https://doi.org/10.2215/CJN.02730312 
Submit or recommend next manuscript to SCIRP and we will provide best service for you:

Accepting pre-submission inquiries through Email, Facebook, LinkedIn, Twitter, etc.

A wide selection of journals (inclusive of 9 subjects, more than 200 journals)

Providing 24-hour high-quality service

User-friendly online submission system

Fair and swift peer-review system

Efficient typesetting and proofreading procedure

Display of the result of downloads and visits, as well as the number of cited articles

Maximum dissemination of your research work

Submit your manuscript at: http://papersubmission.scirp.org/

Or contact ojn@scirp.org 